\title{
Medico-legal medicine: family practice and the latest views on disclosure of information and consent
}

\begin{abstract}
It is not uncommon, when discussing the medico-legal implications of Consent, to lay prominence on surgical intervention and complex medical treatment. Family Medicine, the primary sphere of encounter between patient and healer, far from being the Cinderella of the subject, may well lay the first tier of prevention of confrontation for subsequent specialised treatment. The family practitioner also needs to be conscious of the changing attitudes demanded by Law regarding Consent, and, which, increasingly respect and empower patient awareness and choice. This article evaluates the role of the family physician from a number of aspects vis-à-vis disclosure of information and consent. This includes the infrequently considered advantage of the often greater patient-doctor bonding than found in a hospital setting and the potential of such bonding in avoiding or minimising medico-legal confrontation even involving hospital activity. Furthermore, it may be instrumental in enhancing the discerning aspect of disclosure of information with a view to obtaining genuinely understood consent. The article also looks at the crucial new light thrown on disclosure and consent by the 2015 UK Supreme Court jurisprudential ruling in Nadine Montgomery Appellant against Lanarkshire Health Board Respondent -2015 S.C.C.L.R. 315.
\end{abstract}

Volume 2 Issue 2 - 2018

\author{
George Gregory Buttigieg,' Kirill Micallef \\ Stafrace ${ }^{2}$ \\ 'Faculty of Medicine and Surgery, University of Malta, Malta \\ ${ }^{2}$ Specialist in Family Medicine, University of Malta, Malta \\ Correspondence: George Gregory Buttigieg, Faculty of \\ Medicine and Surgery, University of Malta, Senior Consultant, \\ Malta,Tel +0356 99494474, \\ Email George.g.buttigieg@um.edu.mt
}

Received: November 09, 2017 | Published: March 27, 2018

\section{Introduction}

\section{The danger of "Doctor knows Best"}

The family practitioner often practices in situations involving judicious judgement, deprived of the backing and support of a "hospital firm". The situation has both advantages and disadvantages, and here we look at the practitioner's role in disclosure of information with a view to obtaining consent. The closer patient-doctor relationship often found in a family setting may be tapped with advantage in diminishing the potential for litigation. ${ }^{1}$ On the other hand, it may also engender a false sense of security, which may prove evanescent, when litigation is decided upon. This may be especially so, if fuelled, by ambulancechasing lawyers.

Family practitioners need to be constantly aware of the possibility of legal confrontation. Furthermore they also need to be conscious of changing trends in jurisprudential thinking. And here, one must immediately mention the concept of patient autonomy which gains strength by the day in the face of ever decreasing doctor's paternalistic attitudes. The 'doctor knows best' attitude has long gone out, to be replaced by the patient's choice of what is done to him. This is the jursprudential thinking of the day and it lays much onus on the practitioner to fully explain the treatment proposed, its advantages and risks, any possible alternative treatments and their own pros and cons, and what is likely to ensue if the proposed treatment is not adhered to. There is a serious and urgent need for the family practitioner to pause, reflect and act upon the new implications emanating from the ruking of the 2015 UK High Court in the appeal case of Nadine Montgomery Appellant against Lanarkshire Health Board Respondent. ${ }^{2}$ Lack

${ }^{1}$ Khan MS. Medical Malpractice-Lack of Communication is the Biggest Cause 2013.

${ }^{2}$ Nadine Montgomery Appellant against Lanarkshire Health Board Respondent -2015 S.C.C.L.R. 315. of knowledge of the Law is no excuse for ignoring it and whoever does not familiarise himself with the implications of the case, may be threading very thin ice, if the spectre of serious Court litigation does materialise in any shape or form.

\section{The legal requirements of valid consent}

Consent refers to the principle of valid, acceptance by a patient of any aspect of medical examination, investigation or treatment administered by a healthcare professional. Its crucial basis is recognised both by medical ethics as well as medical law, including international human rights law. The concept of informed consent is embedded in the principles of the Nuremberg Code, the Declaration of Helsinki and the Belmont Report. ${ }^{3}$ No aspect of medical practice may be administered unless consented to by the patient, whether explicitly or implicitly. Thus, going to the family doctor because of a chest cold, carries the implicit consent of physical examination, whereas a surgical intervention will need the explicit consent in writing. Consent given by a patient must be a valid one and such validity is legally recognised, only, if three unassailable conditions are fulfilled. The consent must be voluntary, it must be informed and the patient must have the capacity to understand the information conveyed and use it to make the final informed decision. The voluntary nature of Consent is easy to appreciate. Holding a shotgun at one's head, obviously invalidates the voluntary element. However, coercion may take subtle forms. Thus, pressure may be exerted, by forceful friends or relatives or even medical staff for whatever reason. A surgeon not only advising but goading a patient towards a particular operation may impair Consent. So may pressure from a partner e.g. to proceed with a termination of pregnancy.

${ }^{3}$ Nijhawan LP, Janodia MD, Muddukrishna BS, et al. Informed consent: Issues and challenges. J Adv Pharm Technol Res. 2013;4(3):134-140. 
The indispensable need for a patient to truly understand the disclosed information also stands to common sense. Explaining brain surgery to a four year old or to a comatose patient are extreme examples. Yet, this requirement may provide serious challenge as may happen in a practitioner with limited communication skills for whatever reason. Inability to speak the patient's language may be one example. Some hospitals and GP practices have a most laudatory requirement for physicians to attend communication skill courses. ${ }^{4}$ The problem is an increasing one, with practices catering for migrants and this may still hold in spite of the use of interpreters. The 'informed' aspect of Consent, is the most challenging of the three requirements. It is this part of Consent which has undergone serious changes of implication resulting from the judgement in Nadine Montgomery Appellant against Lanarkshire Health Board Respondent. While there is basis for the purist argument that it is practically impossible to obtain a $100 \%$ legally viable consent form, as based on the full implications of the 'informed' aspect, ${ }^{5}$ practicality must rule the day. Consent templates exist, such as those supplied by the World Health Organisation, ${ }^{6}$ However we recommend that individual practices or family practitioners if they practice solo, use these as guides for their own templates, modified as necessary by local needs. Such individualised templates should be reviewed from time to time and ideally with a medico-legal expert. They should also form part of regular update and discussion sessions of all members of a practice, where such is present. In the present climate, such meetings may prove as clinically valuable as any clinico-pathological sessions.

\section{How informing must the 'informed consent' be?}

At a time where access to informatics rules, at times, it is quite easy for the patient to be better informed about any aspect of treatment than the physician himself. The family practitioner has a serious and daunting task of retaining his onus of responsibility in the aspect of maintaining updated medical knowledge. However, the practitioner must be updated reliably, using such guidelines as those provided by the Colleges, NICE and other authorised bodies. Having to deal with all specialities, unlike the hospital consultant, may make this aspect painfully difficult and it is a must to ensure that the latest information be given as part of the disclosure of information. This does not imply that the family practitioner's responsibility of disclosure encroaches that of the hospital specialist, yet continuity of care at home will automatically draw in the practitioner's involvement rendering management a shared affair. Where the family practitioner is the primary source of disclosure of information for Consent, he must ensure that he:

a. Explains the reasons for the procedure/management/investigation to be undertaken.

b. Explains the procedure itself.

c. Discusses the purported advantages, risks and complications.

d. Evaluates possible alternatives, where they exist, to the proposed treatment.

e. Explains what may ensure if the proposed procedure is not proceeded with

f. At the end of supplying all information, he must stress to the ${ }^{4} \mathrm{http}: / /$ healthcare.findlaw.com/patient-rights/understanding-informed-consenta-primer.html

${ }^{5}$ Buttigieg GG, Buttigieg G. Malta Medical Journal Volume 26 Issue 012014

${ }^{6} \mathrm{http} / / / \mathrm{www}$. who.int/rpc/research ethics/informed consent/en/ patient that the final choice is the patient's.

The ensuing result may not be easy for a medically qualified person to accept e.g. withholding pertussis vaccination in a child on the advice of non -medically qualified persons. Yet accept it, he must. Of the three aspects of validity of consent, disclosure of information probably has the greatest potential for medico-legal confrontation. Although the actual working definition and requirements of the Informed Consent may vary from country to country and from state to state, the spirit is constant - enough information must be given to allow the patient to make an informed choice. Although not all procedures may require the same depth of explanation, the Courts are ever moving in full support of the patient's choice even if this involves eventual detrimental results to the patient's health and life. In family practice, a signed consent is not often required, but where it is, one copy should be kept in the patient's file and one copy should be given to the patient himself or his representative. These documents carry legal import and will be reproduced in Court, if matters reach that stage. In procedures where debate still exists as to the necessity of written consent or not, the family practitioner, be he solo or in group practice, would be advised to play safe and seek written consent.

The latter situation, however rare, may be encountered in the administration of blood or blood derivatives by the family practitioner, who, for example practices in a maternity unit which allows family practice participation. While on the subject, one should note that a 2015 paper by Friedman et $\mathrm{al}^{7}$ revealed surprising and serious potential medico-legal loopholes in transfusing blood/blood derivatives. Researchers such as Margaret Brazier and Anne-Marie Farrell have long and convincingly argued for formalised consent, ${ }^{8}$ a view which in the present authors' view makes most sense. Where the issue evokes argument say within a family practice group, expert medico-legal advice should have the last word. Another example would be whether intra-partum cardio-tocographic monitoring should be covered by a general consent signed on admission to labour ward or whether it should be specifically consented for. We believe that in the present medico-legal climate, it should be specifically consented for, even this is not universal practice. The family practitioner may also be involved in research. The right of adults with sound mind to consent to treatment or risk their own health for the benefit of the community in a clinical trial is unequivocally recognised by the law. ${ }^{9}$ Further discussion of this aspect is beyond the scope of this paper, save to warn that the practitioner thread carefully in matters he may not be fully conversant with, such as ensuring the consent of Ethics Committees and many other aspects, which are best evaluated by experts previous to any clinical involvement.

\section{Informed consent post - 2015}

Nadine Montgomery v Lanarkshire Health Board was an Appeal case before the UK Supreme Court by a patient who had lost her case against in the Scottish Courts in Nadine Montgomery Pursuer against Lanarkshire Health Board Defenders, ${ }^{10} 5$ years previously in 2010. The case involved a vaginal breech delivery of a child who developed

${ }^{7}$ Friedman MT, Bizargity P, Gilmore S, et al. Patient inclusion in transfusion medicine: current perspectives. International Journal of Clinical Transfusion Medicine 2015;3:7-16.

${ }^{8}$ Farrell AM. Consent for blood transfusion BMJ. 2010;341:c4336.

${ }^{9}$ Brazier M, Lobiot M. Protecting the Vulnerable: Autonomy and Consent in Health Care (Social Ethics and Policy) Routledge; 2014.

${ }^{10}$ Nadine Montgomery Pursuer against Lanarkshire Health Board Defenders [2010] CSOH 104. 
Hypoxic Ischaemic Encephalopathy (HIE) and Cerebral Palsy, after delayed delivery due to shoulder dystocia. The Cerebral Palsy was of the spastic quadriplegic dyskinetic form, consistent with HIE. The mother, sought damages on the grounds of negligence and claimed that the outcome could have been avoided by an elective caesarean section. Not only had this safe option not been offered to her, but the obstetrician who had been responsible for both antenatal and intrapartum care, had not evaluated and bothered to do discuss with her the different modes of delivery especially pertaining to her own risk factors. Mrs Montgomery was in fact, a diabetic mother of short stature and was known to be carrying a large infant $(4.25 \mathrm{~kg})$ baby. In spite of all these risk factors, she was never warned about the possibility of shoulder dystocia. The UK Supreme Court ruled against the Scottish Courts and in favour of the plaintiff, rejecting the defendant's argument who basing her argument on the Bolam principle, pleaded her argument on the grounds that her behaviour was on par with what peer medical practice would have done. Although the Scottish Courts had originally ruled for the defendant in 2010, the UK Supreme Court in 2017 awarded Mrs Montgomery the sum of 5.25 million sterling in damages. Among other points, in its judgement, the High Court stated that in seeking consent for a vaginal mode of delivery, the obstetrician should have disclosed all the potential risks and problems of such a birth which, in the case of Mrs. Montgomery, included the substantially higher risk of shoulder dystocia and resultant Cerebral Palsy, which complications did, in fact, come to pass. The case dealt a death blow to the Bolam principle with regard to the disclosure of information.

In truth, the case could have accepted the application of the Bolam principle, which by further application of the Bolitho principle, would have, at least theoretically, failed on the grounds that not many sane obstetricians would have omitted to disclose such crucial information. ${ }^{11}$ However, this was not the outcome. The Bolam principle was actually thrown out as regards disclosure of information (but not as regards diagnosis and treatment). With this, the Court gave its blessing to the concept that doctor does not necessarily know best. Furthermore, henceforth, in jurisprudential decisions about disclosure of medical information, Court would no longer be obliged to seek the advice of peer medical practice. Such matters would now be adjudicated like other professional or trade decisions - at the Court's discretion. The door was now also open for potential future challenges to the Bolam principle as applied to diagnosis and to treatment. ${ }^{12}$ Many queries storm one's mind on reflecting on this legal page turner of a case. One such would be the potential avoidance of the ensuing obstetric disaster had there been shared obstetric care with a discerning and experienced family physician. One does not know whether Mrs Montgomery shared her antenatal anxiety about her delivery, with a family physician. Notwithstanding the many 'ifs' and 'buts', one concludes that a trusted family practitioner might have diplomatically suggested to the obstetrician to think twice about the planned vaginal delivery of a diabetic patient of short stature and carrying a large baby. For common sense is common sense and Mrs Montgomery, herself a graduated scientist, did have serious doubts and anxieties about her birth plan - which doubts and anxieties, she did repeatedly voice to the obstetrician - a point fully endorsed by the defendant obstetrician herself in Court.

${ }^{11}$ Buttigieg GG. Re-visiting Bolam and Bolitho in the light of Montgomery v Lanarkshire Health Board. Medico-Legal Journal; 2017;86(1):42-44.

${ }^{12}$ Badenoch J. A doctor's duty of disclosure and the decline of 'The Bolam Test': A dramatic change in the law on patient consent. Med Leg J. 2016;84(1):5-17.

\section{Conclusion}

The family practitioner in his preferential niche, has a unique understanding of the patient's character, fears, needs, limitations and discernment of what is being proposed. The practitioner is likely to know his patient far better than any hospital consultant and furthermore knows the 'persona' which may never even emerge in hospital settings. This is especially relevant where a patient's vulnerability may impair or limit understanding of disclosed information to enable an informed consent to be given. Such vulnerability may be physical such as in limited vision, cerebral or mental problems of cognition or psychiatric as in bipolar conditions, socio-economic as in immigrants... The family practitioner is also in a masterly position to evaluate the likely genuine understanding of disclosed information (from any source) as based on the patient's circumstances. In turn, the patient who has a sympathetic family practitioner, is likely to be more at ease in communicating with "his" doctor rather than a big shot distant consultant in hospital. Such lack of real or imagined empathy may result in "forgotten" or purposefully hid important medical details such as a past termination of pregnancy. Along the same lines, on being faced with a hospital doctor, the patient may lack the confidence to ask important questions about proposed interventions and procedures and may even Consent against his will, for fear of opposing a strong personality.

Where non-emergency procedures are involved, the family practitioner may act as guardian of the best interests of the patient. He may have to communicate with hospital consultants to be able to advise his patient accurately and truthfully, to comfort, to reassure and to pledge support. But, never, to pressurise. The final choice must be the patient's. The full trust and reliance of some patients on their family practitioner may lay an onus of ethical responsibility that ensures that genuine understanding has been achieved where disclosure of information is involved. If such ethical onus of family practitioner moves pari passu with the legal responsibility of the hospital specialist, much future litigation and even Court action may be altogether avoided. The family practitioner truly knows the patient, in ways far more subtle and complete than the hospital specialist. He may be the one to know the full impact of any proposed treatment which may be beyond the ken of the hospital specialist. The family practitioner may realise, for example, how a protracted post-operative recovery period may tip the financial balance of a precariously balanced socio-economic family situation. His position also makes him privy to positions where he may diplomatically exert the right doses of humanity and prudence as well the necessary advice to deal with a sexually transmissible disease in the family setting. Finally, one needs to bear in mind that no physician is omniscient and there is no shame in stating that there are matters which the doctor himself needs to think about, reflect upon or look up. The family practitioner must cultivate a sincere attitude with the patient and sincerity means that there are times when one admits his all too human failings. No patient expects a superman in his family physician but rather a man "who knows the ropes".. There are circumstances, where the doctor feels the patient has made the wrong decision. If the patient persists in a decision which the doctor feels might be seriously self -detrimental, he would be wise to seek medico-legal advice as to his own protection, confidence and plan of action. However, these steps can only be affected by a family practitioner who, on one hand must be loyal to his patient and his wishes and on the other know the contemporary medico-legal facts to protect his own skin. 


\section{Acknowledgement}

None.

\section{Conflict of interest}

The authors declare there is no conflict of interest. 